\title{
Evaluation of Chitosan and Zinc Oxide Nanoparticles Inhibitory Effects on Expression Levels of Virulence Genes at Pseudomonas aeruginosa Clinical Isolates and ATCC27853

\author{
Mozhgan Pourjafari ${ }^{1}$, Hami Kaboosi $^{1 *}$ iD Masood Ghane $^{2}$ (D) Babak Sadeghi $^{3}$ iD, Abolhasan Rezaei $^{4}$ (D)
}

1. Department of Microbiology, Ayatollah Amoli Branch, Islamic Azad University, Amol, Iran

2. Department of Microbiology, Tonekabon Branch, Islamic Azad University, Tonekabon, Iran

3. Department of Chemistry, Tonekabon Branch, Islamic Azad University, Tonekabon, Iran

4. Department of Genetics, School of Basic Sciences, Tonekabon Branch, Islamic Azad University, Tonekabon, Iran

$10.30699 / i j m m .15 .5 .571$

\section{ABSTRACT}

Background and Aim: Quorum sensing (QS) and virulence genes in Pseudomonas aeruginosa causing severe infections in humans. In the present study, the effect of chitosan (CS) and zinc oxide nanoparticles (ZnO-NPs) on the expression level of lasl, exoS and toxA genes during lag, exponential-and stationary growth phases of $P$. aeruginosa were studied.

Materials and Methods: CS and ZnO-NPs were synthesized by ionic gelation and ultrasonic methods, respectively. The clinical samples were collected from patients suffering from wound infections from 2018-2019, and preliminary identification of $P$. aeruginosa has done with the standard biochemical tests and 165 rDNA gene. The virulence genes (lasl, exoS and toxA) were detected by polymerase chain reaction (PCR). Finally, real-time reverse transcription-PCR (qRT-PCR) was performed to detect the expression level of QS and virulence-related genes in samples grown at a medium contain minimum inhibitory concentrations (MICs) of CS and ZnO-NPs.

Results: CS and ZnO-NPs were successfully prepared with average particle sizes of 20 and $40 \mathrm{~nm}$. The prevalence rate of virulence-related genes among all clinical isolates originated from burn patients was as follows; toxA (100\%), exoS (88\%), and lasl (56\%). The MIC value of CS was equal to $0.5 \mathrm{mg} / \mathrm{mL}$, which is 8 -fold lower than that for ZnO-NPs (4 mg/mL). qRTPCR analysis revealed CS and ZnO-NPs decrease the expression of lasl, exoS, and toxA in clinical $P$. aeruginosa isolates during the exponential phase compared to other growth phases. tox $A^{+} / \mathrm{exoS}^{+} /$las $I^{+}$isolates exhibited similar patterns of gene expression changes in response to both NPs at all growth phases. Expression of tox $A$ gene downregulated at exponentialand stationary growth phases of ATCC27853 treated with CS and ZnO-NPs.

Conclusion: The results obtained from this study may provide a better understanding of the expression changes of virulencerelated genes throughout different growth phases of $P$. aeruginosa.

Keywords: Chitosan, $P$. aeruginosa, Quorum sensing, Zinc oxide nanoparticles

Received: 2021/.7/25; Accepted: 2021/08/10; Published Online: 2021/09/05

Corresponding Information: Hami Kaboosi, Department of Microbiology, Ayatollah Amoli Branch, Islamic Azad University, Amol, Iran.
Email: hkaboosi@gmail.com

(c) (i) (s) Copyright (C) 2021, This is an original open-access article distributed under the terms of the Creative Commons Attribution-noncommercial 4.0 International License which permits copy and redistribution of the material just in noncommercial usages with proper citation.

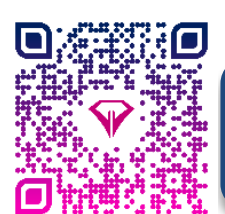

Use your device to scan and read the article online

Download citation: BibTeX | RIS | EndNote | Medlars | ProCite | Reference Manager | RefWorks
Send citation to:
8 Mendeley
2 zotero
(1) RefWorks

\section{Introduction}

$P$. aeruginosa is an opportunistic pathogen that causes infections by exploiting the weakness of the human immune system, especially in patients with severe and immunosuppressive chronic infection $(1,2)$. The ability to grow at simple nutrition supply and temperatures from $4^{\circ} \mathrm{C}$ to $42^{\circ} \mathrm{C}$, resistance to conditions with high concentrations of salts and dyes, weak antiseptics and many commonly used antibiotics are critical factors involved in achieving its prominence as 
community-acquired and $11-13.8 \%$ of all hospitalacquired infections $(2,3)$.

Several model system studies demonstrated that many Gram-negative bacteria like $P$. aeruginosa utilizes types I, II, III, V, and VI secretion systems (TSS) to introduce virulence effector proteins directly into host cells (4). Each TSS is composed of several common secreted factors that play key roles in the pathogenesis of $P$. aeruginosa strains at various infections. Type III secretion systems (TTSS) is a contact-dependent protein secretion pathway with four exoenzymes effectors, ExoS, ExoT, ExoU, and ExoY, which are associated with acute infections of $P$. aeruginosa $(5,6)$. Further investigation showed that one and usually rarely both of the two major exotoxins ExoU and or ExoS express about at all pathogenic strains. In contrast, ExoY and ExoT with minor roles express at most strains. ExoS and ExoU are more common exotoxins in about all invasive and cytotoxic $P$. aeruginosa strains, respectively (6-9). Exotoxin A (ExoA) is considered the most toxic virulence factor and a potent inhibitor of protein synthesis secreted by $P$. aeruginosa. Its injection into the extracellular space through the type II secretory system causes inactivation of elongation factor-2 (EF-2), inhibiting protein synthesis and leading to cell death.

Quorum sensing (QS) is a bacterial mechanism of cellto-cell communication that regulates more than $10 \%$ of genes involved in bacterial growth, many virulence factors production, and adaptation to environmental changes $(6,10)$. QS acts hierarchically through threshold concentrations of small membrane-diffusible molecules called autoinducers (signal molecules). Acylhomoserine lactones (AHLs), including 3-oxododecanoyl homoserine lactone (3-oxo-C12 HSL) and butyryl homoserine lactone (C4 HSL), are common autoinducers in P. aeruginosa produced by the Lasl AHL synthase and Rhll AHL synthase, respectively. Following an increase in bacterial population and diffusion determined concentration of secreted autoinducers into the environment, they subsequently bind to specific transcriptional activators (LasR/RhIR) that trigger expression of genes involved in biofilm formation and coding virulence factors (11).

Recently treatment of $P$. aeruginosa infections has emerged as a big concern considering a broad range of intrinsic, acquired, and adaptive resistance mechanisms. Therefore, therapies aimed at disrupting the QS signaling cascade and biofilm formation have gradually become a promising alternative to conventional antibiotic therapies. The utilization of nanoparticle (NP) potentials has recently received great attention to overcome the ongoing crises caused by antibiotic resistance (12). Chitosan (CS) and zinc oxide nanoparticles (ZnO-NPs) have been greatly considered promising "green" biocides due to their remarkable biological advantages obtained through nanoscale dimensions. These compounds have been characterized as quorum quenchers (QQ) that disturb bacterial communications resulting in inhibits virulence without interfering with the growth. The mechanism of the antibacterial effect of CS and $\mathrm{ZnO}$ on $P$. aeruginosa by targeting the inhibition of $Q S$ and biofilm formation has been reported previously, but gene expression at the mechanism of virulence inhibition following treatment with these NPs being less investigated $(13,14)$. Therefore, it is essential to understand the effectiveness of nanoparticles on the expression of virulence genes to prevent pathogenesis, particularly at the initial stages. The main objectives of this study were to isolate exoS+, toxA+ and las/+ strains from burn patients and investigate the inhibitory effect of CS and ZnO-NPs on expression changes of lasl, exoS, and tox $A$ virulence genes in the mid of lag-, exponentialand stationary growth phases of toxA $A^{+} / \operatorname{exoS}^{+} /$las $^{+} P$. aeruginosa originated from burn patients and ATCC27853 standard strain.

\section{Materials and Methods}

\section{Synthesis of CS Nanoparticles}

CS-NPs were synthesized by ionic gelation according to Calvo's method with slight modifications (20). Briefly, a stock solution of chitosan (Sigma, USA) was dissolved in $0.05 \%(\mathrm{v} / \mathrm{v})$ acetic acid and kept at room temperature under continuous stirring overnight. The $\mathrm{pH}$ of the solution was adjusted to 4.7-4.8. Sodium tripolyphosphate (TPP) (Sigma, USA) was dissolved in ultra-pure water to a concentration of $0.5 \mathrm{mg} / \mathrm{mL}$, filtered (0.22 $\mu \mathrm{m}$, Millipore), and subsequently stirred at $2-4{ }^{\circ} \mathrm{C}$. CS-NPs were formed by adding CS solution dropwise to TPP solution with a volume ratio of $3: 1$ (CS: TPP) and keeping for 15 minutes at room temperature under magnetic stirring (1000 rpm). Then the obtained solution was centrifuged at 13,000 rpm for 20 minutes, and residual TPP was discarded. The CSNP-containing pellets were freeze dried and kept at $4^{\circ} \mathrm{C}$ until further experiments.

\section{Synthesis of ZnO Nanoparticles}

ZnO-NPs were synthesized by the ultrasonic method using $\mathrm{ZnC}_{4} \mathrm{H}_{6} \mathrm{O}_{4}$ (Sigma, USA), Sodium Hydroxide $(\mathrm{NaOH})$, and propylene glycol $10 \%$ as starting materials (21). For synthesis, $0.3 \mathrm{~g}$ of zinc acetate and $0.32 \mathrm{~g}$ of $\mathrm{NaOH}$ were dissolved in $60 \mathrm{~mL}$ of ethanol and exposed to ultrasound for 30 minutes at room temperature. The obtained precipitates were then rinsed with distilled water several times, centrifuged and the remaining solid dried in vacuum desiccators. Finally, different concentrations of ZnO-NPs was resulted by dispersing various concentrations of obtained $\mathrm{ZnO}$ in $10 \%$ propylene glycol.

\section{Characterization of CS and ZnO Nanoparticles}

The morphology and particle size characterization of synthesized NPs were studied using Scanning Electron 
Microscopy (SEM) (TESCAN, MIRA-3) and Transmission Electron Microscopy (TEM) (Zeis, EM1030, Germany). Specimens for TEM analysis were dispersed in ethanol and sonicated in an ultrasonic bath for $20 \mathrm{~min}$. The $\mathrm{X}$-ray power diffraction patterns (XRD) of synthesized compounds were recorded on ( $X^{\prime}$ Pert Pro, Panalytical, UK) with $\mathrm{Cu} \mathrm{K}_{\alpha}$ radiation $(\lambda=1.5412 \AA)$ in the scanning range of $100-800$. To examine the characteristic chemical structure of CS and ZnO-NPs, fourier transform infrared (FTIR) spectra was carried out using JASCO INC 410, Japan, in the range of $400-4000 \mathrm{~cm}^{-1}$.

\section{Sample Collection and Isolation of the Bacteria}

The samples used in this study were collected from Shahid Zare Hospital of Sari, Iran. In this study, patients suffering from wound infections from 2018-2019 were studied. Samples were collected from burn wounds using sterile swabs and immediately transported in $5 \mathrm{~mL}$ of Brain-heart infusion (BHI) broth (Merck, Germany). The $\mathrm{BHI}$ tubes were sent to the clinical laboratory and incubated overnight at $37^{\circ} \mathrm{C}$. Sub-culture was done on nutrient agar media (Merck, Germany) at $37^{\circ} \mathrm{C}$ for 24 hours for subsequent identification.

\section{Phenotypic and Molecular Identification of Isolated Bacteria}

Preliminary identification of $P$. aeruginosa has been done with the standard biochemical tests, including Gram stain, catalase, oxidase, oxidation-fermentation (OF) test, the reaction in triple sugar iron (TSI) agar, growth ability at $42^{\circ} \mathrm{C}$, Pyocyanin pigment production in Mueller-Hinton agar (MHA) (Merck, Germany) and growth on Cetrimide Agar media (15) on positive cultures. In order to molecular identification, the total DNA of overnight bacterial cultures was obtained using the DNeasy bacterial Mini Kit (QIAGEN, Germany), according to the manufacturer's instructions. The quality of extracted DNAs was evaluated on $1 \%$ agarose gel electrophoresis and quantified by NanoDrop ${ }^{\mathrm{TM}} 2000$ system (Thermo Fisher Scientific, USA). PCR amplification of 165 rDNA gene was performed in $25 \mu \mathrm{L}$ reaction mixture containing $14 \mu \mathrm{L}$ dd water, $2.5 \mu \mathrm{L} 10 \times$ PCR buffer, 0.5 $\mu \mathrm{L}$ of dNTPs (10 mM), $0.75 \mu \mathrm{L} \mathrm{MgCl} 2$ (50 mM), $0.25 \mu \mathrm{L}$ Taq polymerase enzyme $(5 \mathrm{U} / \mu \mathrm{L})$ (CinnaGen, Iran) $1 \mu \mathrm{L}$ of each primer (10 pmol) (forward strand primer $5^{\prime}$ GGGGGATCTTCGGACCTCA-3' and reverse strand primer 5'-TCCTTAGAGTGCCCACCCG-3'), and $5 \mu \mathrm{L}(20$ $\mathrm{ng} / \mu \mathrm{l}$ ) of extracted DNA from $P$. aeruginosa isolates using the T100 thermal cycler (Bio-Rad). After an initial denaturation at $95^{\circ} \mathrm{C}$ for $2 \mathrm{~min}$, the reaction mixture was run followed by 30 cycles of $95^{\circ} \mathrm{C}$ for 20 seconds, $58^{\circ} \mathrm{C}$ for 20 seconds, and $72^{\circ} \mathrm{C}$ for 40 seconds, with a final extension at $72^{\circ} \mathrm{C}$ for five min. The indicated primers were produced by TAG Copenhagen (Denmark) and amplifying a $956 \mathrm{bp}$ product of the $16 \mathrm{~S}$ rDNA gene of $P$. aeruginosa (16). $P$. aeruginosa ATCC 27853 was used as positive control and PCR products were visualized by electrophoresis using a $1 \%$ agarose gel stained with ethidium bromide using a UV transilluminator (Kodak Gel Logic 200, USA).

\section{Detection of Virulence Genes by PCR}

PCR amplification of lasl, exoS and toxA virulence genes were performed in $25 \mu \mathrm{L}$ reaction mixture containing14 $\mu \mathrm{L}$ dd water, $2.5 \mu \mathrm{L} 10 \times$ PCR buffer, 0.5 $\mu \mathrm{L}$ of dNTPs (10 mM), $1 \mu \mathrm{L}$ of each primer (10 pmol), $0.75 \mu \mathrm{L} \mathrm{MgCl} 2(50 \mathrm{mM}), 0.25 \mu \mathrm{L}$ Taq polymerase enzyme $(5 \mathrm{U} / \mu \mathrm{L})$ (CinnaGen, Iran) and $5 \mu \mathrm{L}(20 \mathrm{ng} / \mu \mathrm{L})$ of extracted DNA from $P$. aeruginosa isolates. All primers were synthesized by TAG Copenhagen (Denmark) and the sequences of primer sets and amplification conditions are represented in Table 1 and 2 . PCR products were separated using $1 \%$ agarose gel electrophoresis, followed by visualization of stained gel under UV light.

Quantitative assay of the antimicrobial activity and the effect of sub-MIC of CS and ZnO-NPs on bacterial growth

The determination of minimal inhibitory concentrations (MIC) of CS and ZnO-NPs was performed following the standard broth dilution method (CLSI M07A8). For this purpose, serial two-fold dilutions of CS and ZnO-NPs in concentrations ranging from $0.125 \mathrm{mg} / \mathrm{mL}$ to $8 \mathrm{mg} / \mathrm{mL}$ was prepared in Tryptic Soy Broth (TSB) and inoculated with $10 \mu \mathrm{L} P$. aeruginosa culture equivalent to a $0.5 \mathrm{McF}$ Mrland's standard $\left(10^{8} \mathrm{CFU} / \mathrm{mL}\right)$ and incubated overnight at $37^{\circ} \mathrm{C}$. In this study, a medium containing bacterial suspension without NPs and media without bacteria with nanoparticles were used as a positive and negative control, respectively. The lowest concentration of NPs that prevented the visible growth of bacteria was regarded as MIC. One dilution below the MIC was considered the sub-MIC concentration and used for further study (22). For growth curve measurements, diluted overnight clinical $P$. aeruginosa isolates and ATCC 27853 strain in TSB medium were supplemented with sub-MIC concentrations of CS and ZnO-NPs and incubated at $37^{\circ} \mathrm{C}$ under continuous agitation for $24 \mathrm{~h}$. The turbidity of grown bacteria was measured at $600 \mathrm{~nm}$ using a spectrophotometer (Thermo Fisher Scientific, Waltham, MA, USA) at the end of each time interval (23). The experiments were performed in triplicate and the results were reported as the mean \pm SD (standard deviation). 
Table 1. Specific primer sequences targeting lasl, exoS and toxA genes.

\begin{tabular}{ccc|c}
\hline Primer & \multicolumn{1}{c|}{ 5'-sequence-3' $^{\prime}$} & Product size (bp) & Reference \\
\hline \multirow{2}{*}{ lasl } & CACATCTGGGACTCAGC & 171 & $(17)$ \\
ACGGATCATCATCTTCTCC & ATCCTCAGGCGTACATCC & 328 & $(18)$ \\
ACGACGGCTATCTCTCCAC & CACAGGCAACGACGAGGC \\
toxA & CCTTGTCGGGGATGCTGG & 710 & $(19)$ \\
\hline
\end{tabular}

Table 2. The amplification conditions used for the PCR amplification of lasl, exoS and toxA genes in P. aeruginosa.

lasl exos toxA

\begin{tabular}{|c|c|c|c|c|c|c|c|c|c|}
\hline \multicolumn{10}{|c|}{ lasl exos toxA } \\
\hline Steps & 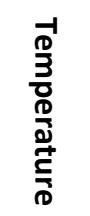 & 록 & $\frac{n}{\frac{1}{D}}$ & $\begin{array}{l}-1 \\
\frac{D}{3} \\
3 \\
\frac{0}{0} \\
\frac{D}{0} \\
\stackrel{D}{D} \\
\frac{D}{D}\end{array}$ & 굴 & $\frac{n}{\alpha}$ & $\begin{array}{l}-1 \\
\frac{D}{3} \\
\frac{3}{0} \\
\frac{D}{0} \\
\frac{D}{D} \\
\frac{C}{D}\end{array}$ & 골 & 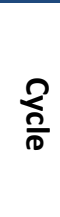 \\
\hline $\begin{array}{l}\text { Primary } \\
\text { denaturation }\end{array}$ & $95^{\circ} \mathrm{C}$ & $2 \min$ & 1 & $94^{\circ} \mathrm{C}$ & $4 \mathrm{~min}$ & 1 & $95^{\circ} \mathrm{C}$ & $5 \mathrm{~min}$ & 1 \\
\hline Denaturation & $95^{\circ} \mathrm{C}$ & $40 \mathrm{sec}$ & \multirow{3}{*}{30} & $94^{\circ} \mathrm{C}$ & $1 \mathrm{~min}$ & \multirow{3}{*}{30} & $95^{\circ} \mathrm{C}$ & $30 \mathrm{sec}$ & \multirow{3}{*}{30} \\
\hline Annealing & $55^{\circ} \mathrm{C}$ & $1 \mathrm{~min}$ & & $55^{\circ} \mathrm{C}$ & $1 \mathrm{~min}$ & & $58^{\circ} \mathrm{C}$ & $30 \mathrm{sec}$ & \\
\hline Extension & $72^{\circ} \mathrm{C}$ & $2 \min$ & & $72^{\circ} \mathrm{C}$ & $2 \mathrm{~min}$ & & $72^{\circ} \mathrm{C}$ & $50 \mathrm{sec}$ & \\
\hline Final extension & $72^{\circ} \mathrm{C}$ & $10 \mathrm{~min}$ & 1 & $72^{\circ} \mathrm{C}$ & $10 \mathrm{~min}$ & 1 & $72^{\circ} \mathrm{C}$ & $10 \mathrm{~min}$ & 1 \\
\hline
\end{tabular}

\section{RNA Extraction and qRT-PCR anaLysis}

qRT-PCR was performed to detect the expression level of QS and virulence-related genes (Iasl, exoS and toxA) in lag-, exponential-and stationary- growth phases of $P$. aeruginosa before and after treatment with CS and ZnO-NPs. Cultivated $P$. aeruginosa in TSB medium before and after supplemented with sub-MIC concentrations of CS and ZnO-NPs until the middle of each lag-( $2 \mathrm{~h})$, exponential ( $8 \mathrm{~h})$-and stationary (18 h) growth phases (OD 600; 0.5 McFarland) were collected for RNA extraction. Total RNA was isolated using Hybrid-R ${ }^{\mathrm{TM}}$ kit (GeneAll Biotechnology, Korea) based on the manufacturer's instructions and stored at $-80^{\circ} \mathrm{C}$. The quality and quantity of extracted RNAs were evaluated using $1.5 \%$ agarose gel electrophoresis and NanoDrop $^{\text {TM }} 2000$ system (Thermo Fisher Scientific, USA), respectively. According to the manufacturer's protocol, extracted RNAs were reverse-transcribed using HyperScript ${ }^{\mathrm{TM}}$ RT premix kit (GeneAll Biotechnology, Korea). PCR was performed on a StepOne Plus machine (Applied Biosystems, USA) using a SYBER Green kit (Ampliqon, Denmark) with specific primers listed in Table 3. The reaction was carried out as follows: holding stage at $95^{\circ} \mathrm{C}$ for $10 \mathrm{~min}$, cycling stage comprising 40 cycles $\left(95^{\circ} \mathrm{C}\right.$ for $15 \mathrm{~s}, 60^{\circ} \mathrm{C}$ for $1 \mathrm{~min}$, $72^{\circ} \mathrm{C}$ for $30 \mathrm{~s}$ ), melt curve stage at $60^{\circ} \mathrm{C}$ for $1 \mathrm{~min}$, and $95^{\circ} \mathrm{C}$ for $15 \mathrm{~s}$. Beacon designer software was utilized for designing primers based on the deduced complete genome sequence of $P$. aeruginosa ATCC 27853 from NCBI (National Centre for Biotechnology Information). The $r p o D$ gene was used as an internal control to normalize the expression of the quantified genes. Gene expression levels in CS and ZnO-treated $P$. aeruginosa was compared to their expression levels in untreated ones using the $2^{-\triangle \Delta \mathrm{Ct}}$ method (24).

Table 3. Primers used in this study for real time PCR of lasI, exoS, txoA and rpoD genes in P. aeruginosa.

\begin{tabular}{|c|c|c|}
\hline Gene & 5'-sequence-3' & References \\
\hline exos & $\begin{array}{c}\text { TCGGCGTCACTGTGGATG } \\
\text { AGAGAGCGAGGTCAGCAGAGTATC }\end{array}$ & This study \\
\hline toxA & $\begin{array}{l}\text { CGAGCAGGCACAACACCTT } \\
\text { CGCACGAGAGCAACGAGAT }\end{array}$ & This study \\
\hline lasI & $\begin{array}{c}\text { CCGCACATCYGGGAACTCA } \\
\text { GATCATCATCTTCTCCACGCCTAC }\end{array}$ & This study \\
\hline rpoD & $\begin{array}{c}\text { GCTGCTGTCGTCGCTTTCTT } \\
\text { AGCATCCTGGCCGACTACAA }\end{array}$ & (25) \\
\hline
\end{tabular}




\section{Statistical Analysis}

Statistical analysis was done using IBM SPSS ${ }^{\circledR}$ Statistics version 19 (IBM ${ }^{\circledR}$ Corp., Armonk, NY, USA). All experiments were performed in triplicate and the data were expressed as mean and standard deviation. The significance of all the statistical tests was determined at $\mathrm{P}$-value $<0.05$.

\section{Results}

\section{Identification of Clinical Isolates}

Twenty-five clinical isolates from one hundred and forty burn samples were identified as $P$. aeruginosa according to phenotypic and biochemical tests. To confirm detected isolates, the presence of $16 \mathrm{~S}$ rDNA gene was investigated by PCR amplification. PCR yielded amplicons with predicted sizes of $956 \mathrm{bp}$ confirmed the existence of $P$. aeruginosa DNA in the same twenty-five isolates (Figure 1).

\section{Detection of Virulence Genes}

The presence of lasl, exoS and toxA virulence genes in $P$. aeruginosa were studied by PCR. The detection results (Figure 2 ) showed that out of $25 P$. aeruginosa isolates identified, only 13 (52\%) were positive for all the three lasl, exoS, and toxA virulence genes. Positive results with toxA and exoS genes were 25 (100\%) and $22(88 \%)$, respectively, while lasl gene was detected only in 14 (56\%) of the collected $P$. aeruginosa isolates.

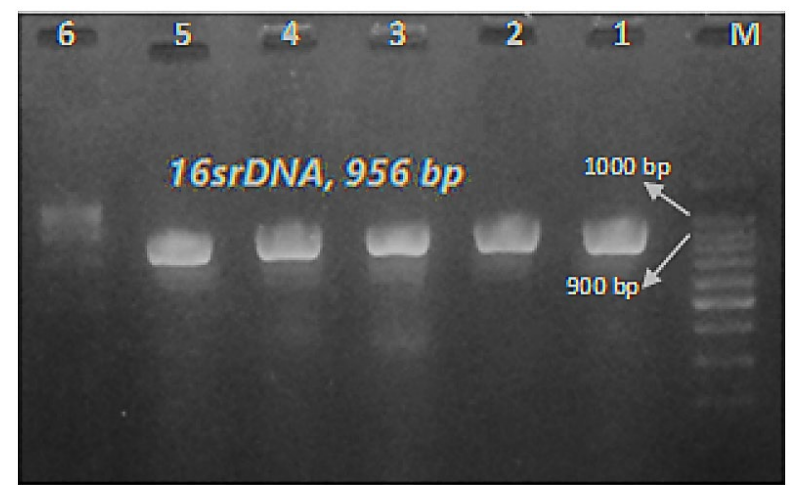

Figure1. Agarose gel (1\%) electrophoresis of PCR products after amplification of $16 \mathrm{~S}$ rDNA gene (956bp); M: GeneRuler 1000 bp DNA Ladder, Fermentas as size marker; N. 1-5: PCR amplification; N.6: Control negative.
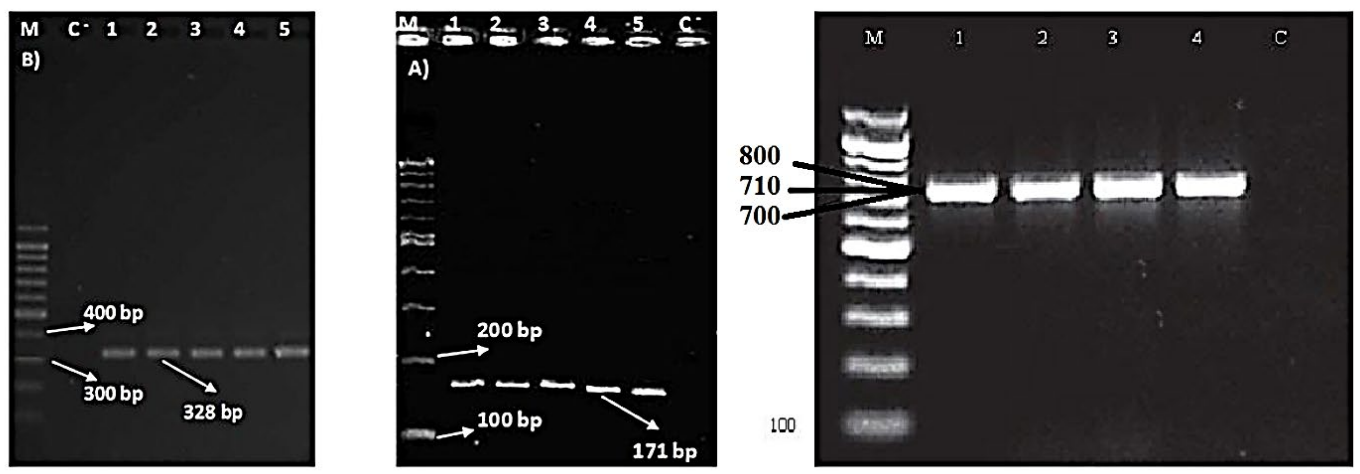

Figure 2. Electrophoresis of $P C R$ products (A) lasl (B) exoS and (C) toxA genes of $P$. aeruginosa clinical isolates in agarose gel.); $M$ : GeneRuler 1000 bp DNA Ladder, Fermentas as size marker; N. 1-5: PCR amplification; C-: Control negative

\section{Characterization of CS and ZnO Nanoparticles}

The structural properties of the CS and ZnO NPs were analyzed using XRD and X'Pert Highscore Plus software. Figure 3 A-D manifests the $X$-ray diffraction patterns of synthesized CS and ZnO-NPs. The definite line broadening in the XRD patterns of both CS and $\mathrm{ZnO}$ indicates that the prepared particles were in the nanoscale range. Diffraction peaks appeared at $2 \theta=$ $11.7^{\circ}$ and $2 \theta=19.8^{\circ}$ agreed with previous reports (2628) and can be indexed to the successful synthesis of CS-NPs (Figure 3A). The characteristic of broad peaks with $2 \theta$ values of $31.66^{\circ}, 34.3^{\circ}, 36.2^{\circ}, 47.4^{\circ}, 56.5^{\circ}$, $62.8^{\circ}, 66.3^{\circ}, 67.8^{\circ}$ and $68.8^{\circ}$ corresponding to the hexagonal wurtzite structure of $\mathrm{ZnO}-\mathrm{NPs}$ confirmed using JCPDS card number 96-900-8878 (Figure 3B) (29). IR characterization of CS and ZnO-NPs were acquired in the range of $400-4000 \mathrm{~cm}^{-1}$, and the spectra are shown in Figure 2. The CS-NPs showed a peak at $3449 \mathrm{~cm}^{-1}$ attributed to stretching vibration of $-\mathrm{NH} 2,-\mathrm{OH}$ groups and the enhanced hydrogen bonding of nanoparticles (Figure $3 \mathrm{C}$ ). The sharp peaks located at $1658 \mathrm{~cm}^{-1}$ and $1557 \mathrm{~cm}^{-1}$ can be attributed to the formation of $-\mathrm{NH}^{+}$and cross-linkage with phosphate groups of TPP. The spectra of CS-NP showed peaks at 1157 and $1073 \mathrm{~cm}^{-1}$ can be attributed to the stretching of the $\mathrm{C}-\mathrm{O}-\mathrm{C}$ bridge and $\mathrm{P}=\mathrm{O}$ stretching vibration from phosphate groups, respectively $(30,31)$. The spectral features of $\mathrm{ZnO}-\mathrm{NPs}$ (Figure 3D) are as follows: absorption at $3391 \mathrm{~cm}^{-1}$ corresponding to the stretching vibrations of the $-\mathrm{OH}$ group on the surface of ZnO-NPs, $1641 \mathrm{~cm}-1$ related to asymmetric stretching of zinc carboxylate $(C=O)$ (32), and a signature band at $582 \mathrm{~cm}^{-1}$ as the characteristic stretching mode of $\mathrm{Zn}-\mathrm{O}$ bond (33-35). The sharp bands assigned to - $\mathrm{CO}$ stretching vibration 
and the existence of metal were found at 946 and $1004 \mathrm{~cm}-1$ (36).

Figure $4(A, B, C$ and $D)$ shows the TEM and SEM micrographs of the surface morphological structure of CS and ZnO-NPs. The TEM of CS-NPs (Figure 4A) shows CS-NPs having a spherical shape without agglomeration and an average particle size range of about $20 \mathrm{~nm}$. The
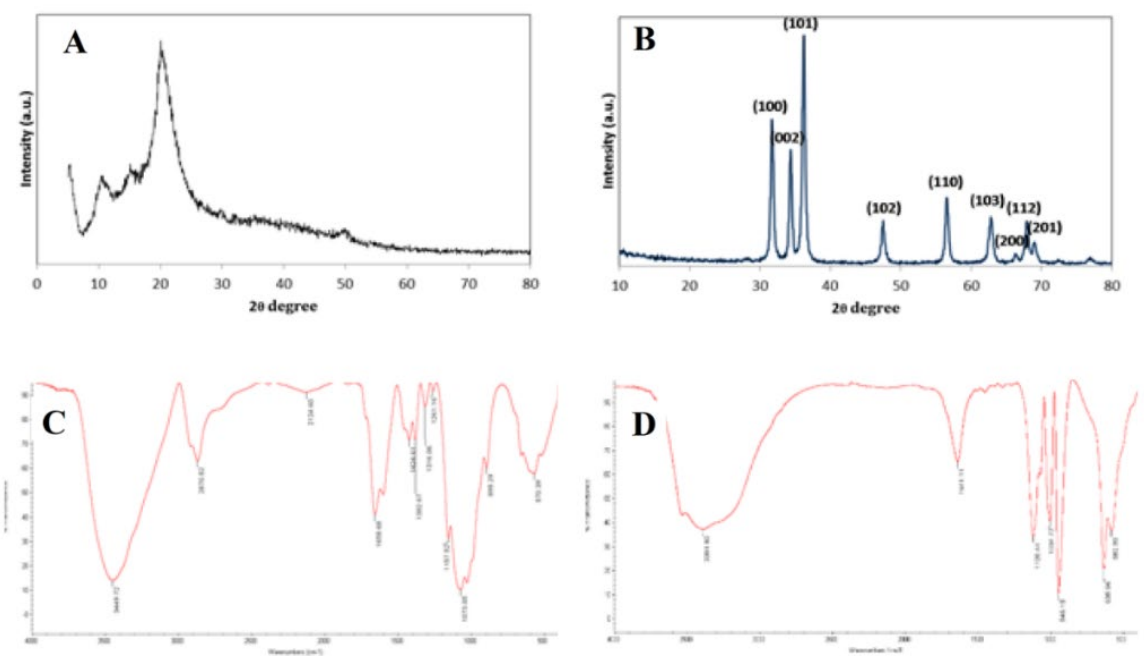

Figure 3. XRD patterns of CS-NPs (A) and ZnO-NPs (B). Fourier-transform infrared spectrum of CS-NPs (C) and ZnO-NPs (D).
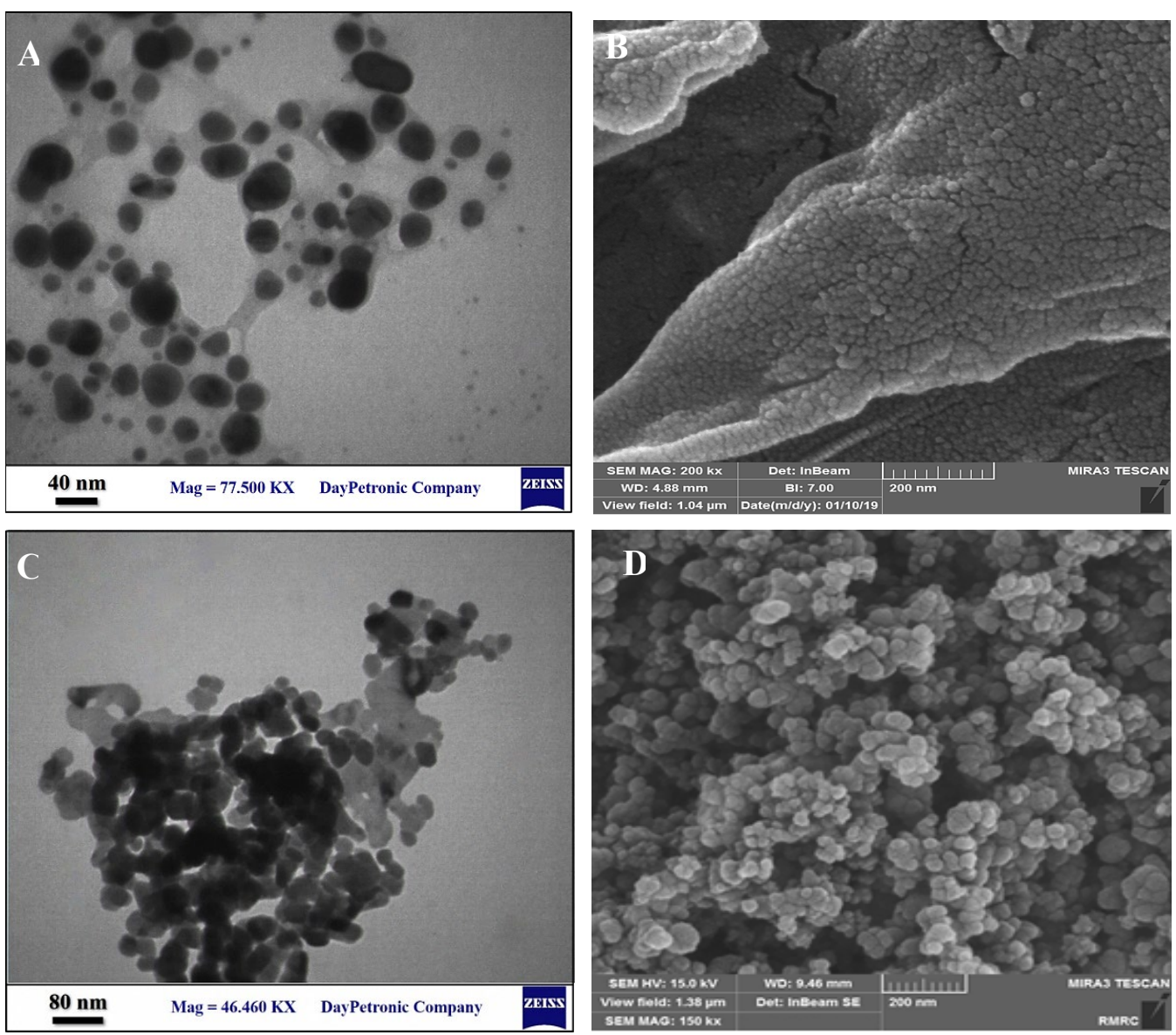

Figure 4. TEM of CS-NPs (A), SEM of CS-NPs (B), TEM of ZnO-NPs (C), and SEM of ZnO-NPs 


\section{Determination of Antimicrobial Activity of NPs and Growth Inhibition Assay}

The MIC of CS and ZnO-NPs have been measured on the $13 P$. aeruginosa strains possessed tox $A^{+} /$exo $^{+} /$las $^{+}$ genotype and ATCC 27853 as the standard strain on TSB media containing selected serial concentrations of NPs. In this study, treatment with NPs did not show a similar inhibitory effect at a certain concentration for all the tested clinical isolates. The MIC values of CS and $\mathrm{ZnO}$ NPs were found to be $0.5 \mathrm{mg} / \mathrm{mL}$ and $4 \mathrm{mg} / \mathrm{mL}$ for five clinical isolates, respectively, while the growth of the rest of the isolates was inhibited at the lower concentrations of mentioned NPs. Therefore, five clinical isolates harboring tox $\mathrm{A}^{+} / \mathrm{exoS}^{+} / \mathrm{las}^{+}$genotype that showed higher resistance to NPs were selected for further analysis. The MIC values of CS and ZnO-NPs were equal to $0.125 \mathrm{mg} / \mathrm{mL}$ and $2 \mathrm{mg} / \mathrm{mL}$ for standard strain, respectively (data not shown).

0.25 and $2 \mathrm{mg} / \mathrm{mL}$ were used as sub-MIC for clinical isolates and 0.0625 and $1 \mathrm{mg} / \mathrm{mL}$ for ATCC 27853 to evaluate their inhibitory effect on growth performance and virulence factors. As a result, ATCC 27853 standard strain showed higher susceptibility to both NPs than clinical isolates in which CS-NP possess higher inhibition activity. The graph shown in Figure 5 depicted the growth inhibition of bacteria supplemented in media containing the respective sub-MIC of NPs. The difference in growth rates of standard and clinical isolates was not statistically significant before and after treatment of CS and ZnO-NPs ( $P>0.05)$. Sub-MIC of CSNPs showed a greater decrease in the growth rate than ZnO-NPs $(P>0.05)$.

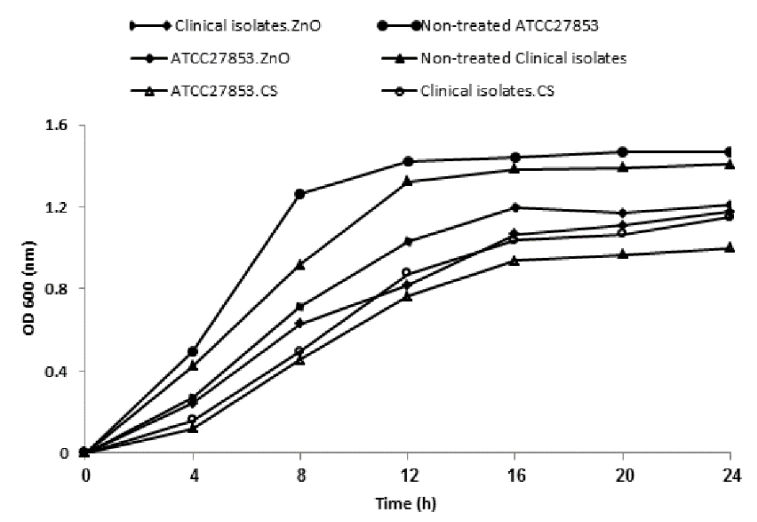

Figure 5. The growth curve of clinical $P$. aeruginosa isolates and ATCC 27853 before and after treatment with sub-MIC of NPs. Value of the clinical isolates is expressed by the mean of five selected resistance isolates.

\section{Expression of QS and Virulence-related Genes in Response to CS and ZnO-NPs at Different Growth Phases}

The relative expression of lasl, exoS, and toxA genes was assessed at the middle of each lag-, exponentialand stationary-growth phases of bacteria in medium supplemented with and without sub-MICs of CS and ZnO-NPs. CS and ZnO-NPs showed a down-regulation with relative expression levels of 0.802 - and 0.706 -fold change for lasl gene in the exponential growth phase of clinical isolates while in standard strain was increased by 1.21 and 1.07 folds, respectively (Figure 6 A-D). On the contrary, lasl expression level was increased with relative transcriptional levels of 1.048, 1.037- and 2.72-, 1.67-fold change in lag and stationary phases of clinical isolates treated with CS and ZnO-NPs, respectively, compared to a standard strain (Figure $6 \mathrm{~A}$ and D). For CS-NPs, the level of exoS and toxA genes expression in clinical isolates was reduced by 0.699 and 0.962 folds in the exponential growth phase and increased with relative transcriptional levels of 1.15-, 1.194- and 1.131-, 1.02fold change in lag and stationary phases, respectively (Figure $6 \mathrm{~B}$ and C). ZnO-NPs inhibited the expression of exoS and toxA genes in clinical isolates as their expression was decreased by 0.604 and 0.765 folds in the exponential growth phase, respectively (Figure $6 \mathrm{E}$ and $F$ ). The fold change in the expression of exoS and tox $A$ genes was 1.53, 1.42, and 1.2, 0.9-fold in lag and stationary phases of clinical isolates treated with $\mathrm{ZnO}$ NPs, respectively. For the standard strain treated with ZnO-NPs, expression of exoS gene showed upregulation during all phases while expression of toxA gene was downregulated except for lag phase (1.43-fold) (Figure $6 \mathrm{E}$ and F). 


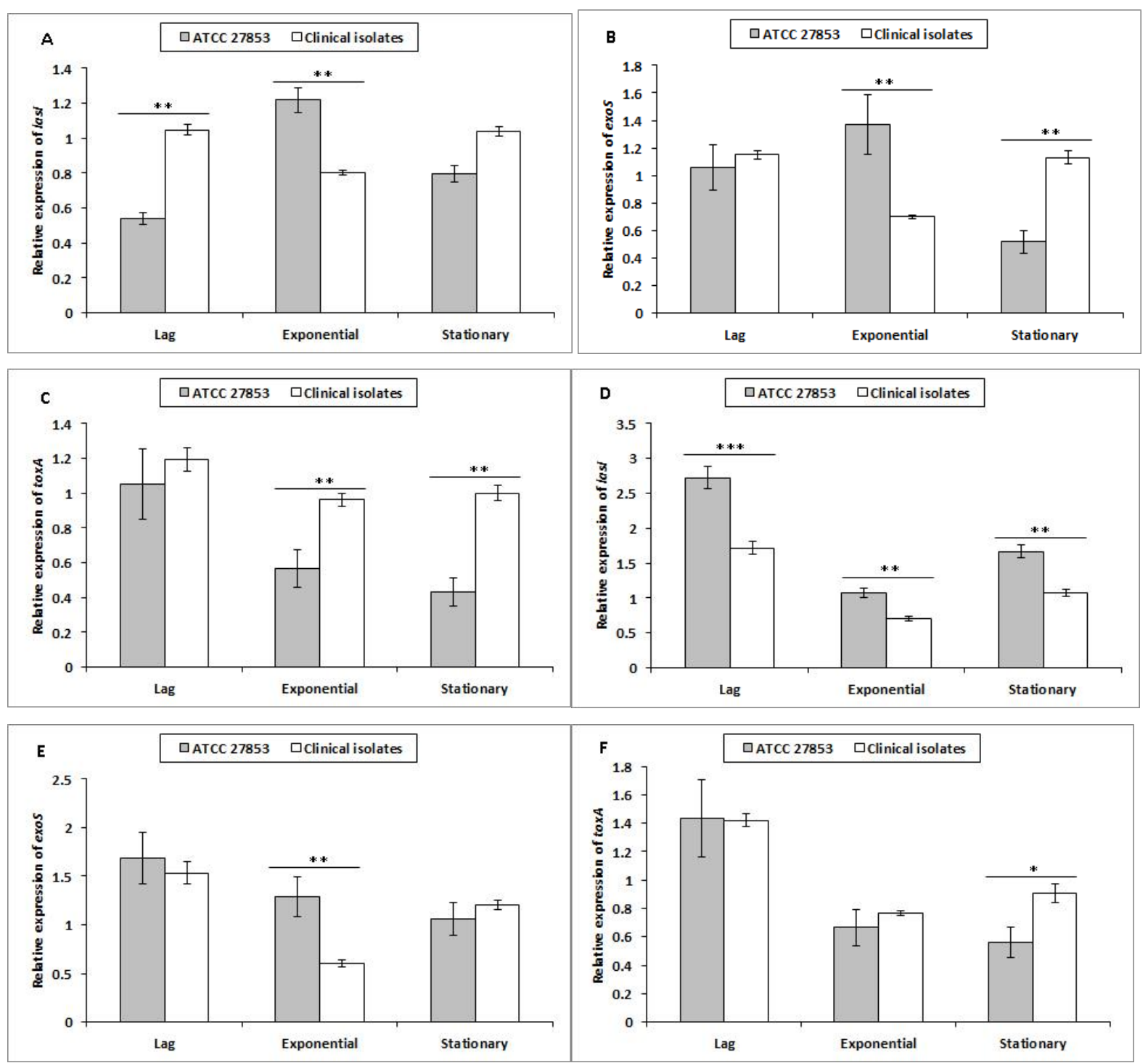

Figure 6. The relative expression of lasl, exoS and toxA genes in clinical $p$. aeruginosa isolates and ATCC 27853 after treatment with CS-NPs ( $A, B$ and C) and ZnO-NPs (D, E and F) at lag-, exponential-and stationary-growth phases. The data of three replicates shown as the means \pm SD (value of the clinical isolates is expressed by mean of five selected resistance isolates). Significant differences between clinical $p$. aeruginosa isolates and ATCC 27853 were determined by $t$-test; ${ }^{*} P<0.05, * * P<0.01, * * * P<0.001$.

\section{Discussion}

Understanding the inhibitory effect of NPs on the expression of virulence dependent genes at different growth phases of $P$. aeruginosa can be an effective alternative approach to antibacterial therapies and overcome infection through interrupting and/or blocking expression of QS-regulated virulence factors (36).

Emerging of multi-drug resistant (MDR) $P$. aeruginosa strains due to their innate and acquired resistance mechanisms and excessive and indiscriminate use of antibiotics have led to difficult treatment, high morbidity, and mortality, especially in burn-infected patients (37).

To confirm the evaluation of CS and ZnO-NPs effects on the expression of $P$. aeruginosa virulence factors, the presence of Iasl, exoS and toxA genes was first investigated by $P C R$ and isolates containing all three genes were selected for qRT-PCR analysis. In our study, the presence of toxA, exoS and lasl genes was detected in $100 \%, 88 \%$ and $56 \%$ of all the burn clinical isolates, respectively. In studies by Yousefi-Avarvand et al. and Amirmozafari et al. the prevalence of toxA among the clinical isolates of $P$. aeruginosa was reported $90.4 \%, 97 \%$ and $66.7 \%, 59.8 \%$ for exoS, respectively $(4,10)$.

Nikbin et al. reported the frequency of toxA and exoS genes for 100 clinical isolates from burn-infected patients to be $97 \%$ and $67 \%$ (38). Our findings showed a high prevalence of virulence-related markers in which $52 \%$ of isolates harboring all the three lasl, exoS 
and toxA that was almost in line with the findings of other studies from various parts of Iran.

Similar to other results, increased frequency of isolates possessing both toxA and exoS toxin genes in this study may confirm their possible contributory role associated with causing infection and emerging resistance strains in burn patients (4). In this study, 13 clinical isolates harboring tox $\mathrm{A}^{+} / \mathrm{exoS}^{+} / \mathrm{las}^{+}$genotype were subjected to further study. NPs and their nanocomposites especially combine with antibiotics due to their many enhanced properties and excellent biological activities being considered novel nanotherapeutic approaches to overcome infections caused by multidrug-resistant organisms (39). Therefore, the present study was conducted to evaluate the effects of CS and ZnO -NPs on growth performance, QS and virulence-related gene expression at different growth phases in $P$. aeruginosa.

According to the XRD and FTIR results, all characteristic absorption and diffraction patterns indicated purity and the crystalline structures of obtained CS and ZnO-NPs, similar to previously reported literature $(34,35)$. TEM and SEM micrographs indicated spherical structure, network formation and agglomeration of synthesized CS and ZnO-NPs that confirmed with the results obtained from XRD.

CS and ZnO-NPs as organic- and inorganic-based nanomaterials are currently studied among the most widely used antimicrobial agents against a wide spectrum of bacterial species as well as $P$. aeruginosa compared to their counterparts. Nanoparticledependent antibacterial mechanisms directly correlate with particle size and concentration, where smaller size and higher concentrations of nanoparticles displayed better antimicrobial activity (40). According to literature reports, $P$. aeruginosa strains are susceptible to CS-NPs with MIC values ranging from 128 to 4096 $\mu \mathrm{g} / \mathrm{mL}$ (41), indicating that the MIC values of 0.125 and $0.5 \mathrm{mg} / \mathrm{mL}$ obtained in our studies for standard and clinical isolates are favorable due to the range in which they are. The values of $1600-3200 \mu \mathrm{g} / \mathrm{mL}(42), 375$ $\mu \mathrm{g} / \mathrm{mL}$ (43), $128 \mu \mathrm{g} / \mathrm{mL}$ and $300 \mathrm{mM}$ (44) has been previously reported as MIC of ZnO-NPs for $P$. aeruginosa depending on the size, stability, and concentration of agent as well as MIC determination methods and growth medium (45). In our study, NPs exhibited concentration-dependent antimicrobial activity against identified isolates with tox $A^{+} / \operatorname{exoS}^{+} /$las ${ }^{+}$ genotypes in which at five isolates, the growth was inhibited at higher concentrations of NPs. ZnO-NPs prevented the growth of tested standard strain and five clinical isolates at concentrations of $2 \mathrm{mg} / \mathrm{mL}$ and 4 $\mathrm{mg} / \mathrm{mL}$, respectively. Our finding is rather close to those reported by C. de Souza et al. (46) (up to $2 \mathrm{mg} / \mathrm{mL}$ ) for ATCC 27853 standard strain. In case of clinical isolates exception for the value reported by Saleh et al. (47), other reported values were lower than the MIC value observed in the present work. In agreement with other studies $(42,48)$, both NPs showed a lower activity towards the clinical isolates. CS-NPs were able to inhibit the growth of $P$. aeruginosa at a lower concentration than ZnO-NPs.

lasl, exoS and toxA are major QS and virulencerelated genes involved in the $P$. aeruginosa pathogenesis (8). Several publications have been well studied the potential of $\mathrm{ZnO}$ and CS-NPs to prevent virulence factor production and biofilm formation through various mechanisms against $P$. aeruginosa (14, $36,49)$. We further study the effect of synthesized $\mathrm{ZnO}$ $(40 \mathrm{~nm})$ and CS $(20 \mathrm{~nm})$ NPs on the expression level of lasl, exoS and toxA virulence-related genes of five $P$. aeruginosa $\left(\right.$ tox $A^{+} / \mathrm{exoS}^{+} / \mathrm{las}^{+}$) originated from burn patients compare to ATCC 27853 standard stain. To the best of our knowledge, this is the first study to evaluate the expression of mentioned genes with an emphasis on lag-, exponential and stationary-growth phases of $P$. aeruginosa from burn patients.

In the present study, Iasl, exoS, and toxA genes were downregulated due to CS and ZnO-NPs treatment in the exponential phase of clinical isolates with the higher inhibitory effect for CS compared to ZnO-NPs. Similarly, it was proved by Badawy et al. (36) that CSNP down-regulated the expression of lasl. A similar study by Singh et al. (49), Rao et al. (48), and Saleh et al. (47) supported our results, where ZnO-NPs showed an inhibitory effect on lasl expression level. Furthermore, in ATCC 27853, except for toxA, lasl and exoS genes showed upregulation at the exponential phase. On the other hand, these genes showed upregulation during the lag and stationary phases in clinical isolates. A similar gene expression pattern was observed for toxA in treated CS and ZnO tox $A^{+} /$exoS $^{+} /$lasl $l^{+}$isolates and ATCC 27853 during all growth phases. Our results showed that sub-MIC concentration of CS and $\mathrm{ZnO}-\mathrm{NPs}$ could decrease the expression of QS-mediated virulence factors only during the exponential phase compared to the other growth phases in clinical isolates. The sub-MIC concentration of CS and ZnO-NPs exhibited similar expression changes for toxA, lasl, and exoS genes during lag, exponential and stationary phases of tox $A^{+} /$exoS $^{+} /$las $^{+} P$. aeruginosa isolates compared to ATCC 27853. In the current study, although the subMIC concentration of CS was lower than ZnO-NPs, its inhibitory effect on expression level was more than those induced that by ZnO-NPs. This is due to the positively charged and small size of CS-NPs.

\section{Conclusion}

In conclusion, this study is the first to examine the inhibitory effects of CS and ZnO-NPs on the expression of lasl, exoS and toxA virulence genes during lag-, 
exponential- and stationary-growth phases in $P$. aeruginosa. The synthesized CS and ZnO-NPs successfully downregulated QS and virulence-related gene expression in the exponential growth phase relative to lag and stationary phase. Gene expression patterns of lasl, exoS and toxA were varied between tox $A^{+} / \operatorname{exoS}^{+} /$lasl $^{+} P$. aeruginosa isolates and ATCC 27853 at different growth phases. The higher inhibitory effect of CS-NPs on lasl, exoS and toxA gene expression levels was observed compared to ZnO-NPs. The results of this study can be useful for a better understanding of the inhibitory effects of NPs at overcoming $P$. aeruginosa harboring lasl, exoS and toxA virulence genes.

\section{Acknowledgments}

Thesis advisors Masood Ghane and Hami Kabossi are acknowledged and appreciated extremely in the research process as well as all employees of the

\section{References}

1. Diggle SP, Whiteley M. Microbe Profile: Pseudomonas aeruginosa: opportunistic pathogen and lab rat. Microbiology (Reading, England). 2020;166(1):30-3. [DOI:10.1099/mic.0.000860] [PMID] [PMCID]

2. $\mathrm{Wu} \mathrm{M}$, Li $\mathrm{X}$. Klebsiella pneumoniae and Pseudomonas aeruginosa. Molecular medical microbiology: Elsevier; 2015. p. 1547-64. [DOI:10.1016/B978-0-12-397169-2.00087-1]

3. LaBauve AE, Wargo MJ. Growth and laboratory maintenance of Pseudomonas aeruginosa. Current protocols in microbiology. 2012; Chapter 6:Unit 6E.1.[PMID] [PMCID] [DOI:10.1002/9780471729259.mc06e01s25]

4. Yousefi-Avarvand A, Khashei R, Sedigh EbrahimSaraie H, Emami A, Zomorodian K, Motamedifar $M$. The Frequency of Exotoxin $A$ and Exoenzymes $S$ and $U$ Genes Among Clinical Isolates of Pseudomonas aeruginosa in Shiraz, Iran. International journal of molecular and cellular medicine. 2015;4(3):167-73.

5. Kroken AR, Chen CK, Evans DJ, Yahr TL, Fleiszig SMJ. The Impact of ExoS on Pseudomonas aeruginosa Internalization by Epithelial Cells Is Independent of fleQ and Correlates with Bistability of Type Three Secretion System Gene Expression. mBio. 2018;9(3). [DOI:10.1128/mBio.00668-18] [PMID] [PMCID]

6. Gellatly SL, Hancock RE. Pseudomonas aeruginosa: new insights into pathogenesis and host defenses. Pathogens and disease.
Microbiology Research Laboratory ward in the Islamic Azad University of Tonekabon Branch.

The study protocol approval was provided by the Ethics Committee of Islamic Azad University of Tonekabon (IR.IAU.TON.REC.1399.014).

\section{Author Contribution}

Mozhgan Pourjafari Collected the data and wrote the paper. Hami Kaboosi conceived and planned the experiments. Masood Ghane Conceived and designed the analysis and collected the data. Babak Sadeghi, Abolhasan Rezaei verified and performed the analysis.

\section{Conflict of Interest}

The authors do not report any financial or personal connections with other persons or organizations, which might negatively affect the contents of this publication and/or claim authorship rights to this publication.

\section{3;67(3):159-73. 632X.12033] [PMID]}

7. Shaver CM, Hauser AR. Relative contributions of Pseudomonas aeruginosa ExoU, ExoS, and ExoT to virulence in the lung. Infect Immun. 2004;72(12):6969-77.

[DOI:10.1128/IAI.72.12.6969-6977.2004] [PMID] [PMCID]

8. Karthikeyan RS, Priya JL, Leal SM, Jr., Toska J, Rietsch A, Prajna V, et al. Host response and bacterial virulence factor expression in Pseudomonas aeruginosa and Streptococcus pneumoniae corneal ulcers. PLoS One. 2013;8(6):e64867. [PMID] [PMCID] [DOI:10.1371/journal.pone.0064867]

9. Subedi D, Vijay AK, Kohli GS, Rice SA, Willcox M. Association between possession of ExoU and antibiotic resistance in Pseudomonas aeruginosa. PLoS One. 2018;13(9):e0204936. [DOI:10.1371/journal.pone.0204936] [PMID] [PMCID]

10. Amirmozafari N, Fallah Mehrabadi J, Habibi A. Association of the Exotoxin A and Exoenzyme $S$ with Antimicrobial Resistance in Pseudomonas Aeruginosa Strains. Arch Iran Med. 2016;19(5):353-8.

11. Rocha AJ, Barsottini MRdO, Rocha RR, Laurindo MV, Moraes FLLd, Rocha SLd. Pseudomonas aeruginosa: virulence factors and antibiotic resistance genes. Brazilian Archives of Biology 
and Technology. 2019;62. [DOl:10.1590/16784324-2019180503]

12. Younes N, Pintus G, Al-Asmakh M, Rasool K, Younes S, Calzolari S, et al. "Safe" Chitosan/Zinc Oxide Nanocomposite Has Minimal OrganSpecific Toxicity in Early Stages of Zebrafish Development. ACS biomaterials science \& engineering. 2020;6(1):38-47.

[DOI:10.1021/acsbiomaterials.8b01144] [PMID]

13. García-Lara B, Saucedo-Mora $M$, RoldánSánchez JA, Pérez-Eretza B, Ramasamy M, Lee J, et al. Inhibition of quorum-sensing-dependent virulence factors and biofilm formation of clinical and environmental Pseudomonas aeruginosa strains by ZnO nanoparticles. Letters in applied microbiology. 2015;61(3):299-305. [DOI:10.1111/lam.12456] [PMID]

14. Lee JH, Kim YG, Cho MH, Lee J. ZnO nanoparticles inhibit Pseudomonas aeruginosa biofilm formation and virulence factor production. Microbiological research. 2014;169 (12):888-96.

[DOI:10.1016/i.micres.2014.05.005] [PMID]

15. Igawa G, Casey M, Sawabe E, Nukui Y, Okugawa $\mathrm{S}$, Moriya $\mathrm{K}$, et al. Comparison of agar dilution and broth microdilution methods for Clostridium difficile antimicrobial susceptibility testing. Journal of global antimicrobial resistance. 2016;7:43-5.

[DOI:10.1016/j.jgar.2016.07.007] [PMID]

16. Spilker T, Coenye T, Vandamme P, LiPuma JJ. PCR-based assay for differentiation of Pseudomonas aeruginosa from other Pseudomonas species recovered from cystic fibrosis patients. Journal of clinical microbiology. 2004;42(5):2074-9. [PMID] [PMCID] [DOI:10.1128/JCM.42.5.20742079.2004]

17. Wargo MJ, Hogan DA. Examination of Pseudomonas aeruginosa lasl regulation and 3oxo-C12-homoserine lactone production using a heterologous Escherichia coli system. FEMS microbiology letters. 2007;273(1):38-44. [DOI:10.1111/i.1574-6968.2007.00773.x] [PMID]

18. Macin S, Akyon Y. Phenotypic and genotypic virulence factors in Pseudomonas aeruginosa strains according to pigment presence. ACTA MEDICA MEDITERRANEA. 2017;33(6):1033-8.

19. Amirmozafari N, Fallah Mehrabadi J, Isazadieh $\mathrm{K}$, Habibi A. Molecular analysis of exotoxin A associated with antimicrobial resistance of Pseudomonas aeruginosa strains isolated from patients in Tehran hospitals. Iranian Journal of Medical Microbiology. 2015;8(4):36-43.

20. Calvo P, Remunan-Lopez C, Vila-Jato JL, Alonso M. Novel hydrophilic chitosan-polyethylene oxide nanoparticles as protein carriers. Journal of applied polymer science. 1997;63(1):125-32. [DOI:10.1002/(SICI)10974628(19970103)63:13.0.CO;2-4]

21. Haase $M$, Weller $H$, Henglein A. Photochemistry and radiation chemistry of colloidal semiconductors. 23. Electron storage on zinc oxide particles and size quantization. The Journal of Physical Chemistry. 1988;92(2):4827. [DOI:10.1021/i100313a047]

22. Parvekar P, Palaskar J, Metgud S, Maria R, Dutta $\mathrm{S}$. The minimum inhibitory concentration (MIC) and minimum bactericidal concentration (MBC) of silver nanoparticles against Staphylococcus aureus. Biomaterial investigations in dentistry. 2020;7(1):105-9. [PMID] [PMCID] [DOI:10.1080/26415275.2020.1796674]

23. Luo J, Kong JL, Dong BY, Huang $\mathrm{H}$, Wang $\mathrm{K}, \mathrm{Wu}$ $\mathrm{LH}$, et al. Baicalein attenuates the quorum sensing-controlled virulence factors of Pseudomonas aeruginosa and relieves the inflammatory response in $P$. aeruginosainfected macrophages by downregulating the MAPK and NFKB signal-transduction pathways. Drug design, development and therapy. 2016;10:183-203. [DOI:10.2147/DDDT.S97221] [PMID] [PMCID]

24. Livak KJ, Schmittgen TD. Analysis of relative gene expression data using real-time quantitative PCR and the 2(-Delta Delta $C(T)$ ) Method. Methods. 2001;25(4):402-8. [DOI:10.1006/meth.2001.1262] [PMID]

25. Janjua HA, Segata N, Bernabò $P$, Tamburini $S$, Ellen $A$, Jousson $O$. Clinical populations of Pseudomonas aeruginosa isolated from acute infections show a wide virulence range partially correlated with population structure and virulence gene expression. Microbiology (Reading, England). 2012;158(Pt 8):2089-98. [DOI:10.1099/mic.0.056689-0] [PMID]

26. Kumar S, Koh J. Physiochemical, optical and biological activity of chitosan-chromone derivative for biomedical applications. Int J Mol Sci. 2012;13(5):6102-16. [DOI:10.3390/ijms13056102] [PMID] [PMCID]

27. Trung TS, Thein-Han WW, Qui NT, Ng CH, Stevens WF. Functional characteristics of shrimp chitosan and its membranes as affected by the degree of deacetylation. Bioresource 
technology. 2006;97(4):659-63.

[DOI:10.1016/i.biortech.2005.03.023] [PMID]

28. Julkapli NM, Ahmad Z, Akil HM, editors. X-Ray Diffraction Studies of Cross Linked Chitosan With Different Cross Linking Agents For Waste Water Treatment Application. AIP Conference Proceedings; 2010: American Institute of Physics. [DOI:10.1063/1.3295578]

29. Soleimani H, Baig MK, Yahya N, Khodapanah L, Sabet M, Demiral BM, et al. Synthesis of $\mathrm{ZnO}$ nanoparticles for oil-water interfacial tension reduction in enhanced oil recovery. Applied Physics A. 2018;124(2):1-13.

[DOI:10.1007/s00339-017-1510-4]

30. Lustriane C, Dwivany FM, Suendo V, Reza M. Effect of chitosan and chitosan-nanoparticles on post harvest quality of banana fruits. Journal of Plant Biotechnology. 2018;45(1):36-44. [DOI:10.5010/JPB.2018.45.1.036]

31. Rosyada A, Sunarharum W, Waziiroh E, editors. Characterization of chitosan nanoparticles as an edible coating material. IOP Conference Series: Earth and Environmental Science; 2019: IOP Publishing.

[DOI:10.1088/17551315/230/1/012043]

32. Rajendran SP, Sengodan K. Synthesis and characterization of zinc oxide and iron oxide nanoparticles using Sesbania grandiflora leaf extract as reducing agent. Journal of Nanoscience.

2017;2017. [DOI:10.1155/2017/8348507]

33. Mallakpour S, Madani M. Use of silane coupling agent for surface modification of zinc oxide as inorganic filler and preparation of poly (amideimide)/zinc oxide nanocomposite containing phenylalanine moieties. Bulletin of Materials Science. 2012;35(3):333-9.

\section{[DOI:10.1007/s12034-012-0304-8]}

34. Handore K, Bhavsar S, Horne A, Chhattise P, Mohite K, Ambekar J, et al. Novel green route of synthesis of $\mathrm{ZnO}$ nanoparticles by using natural biodegradable polymer and its application as a catalyst for oxidation of aldehydes. Journal of Macromolecular Science, Part A. 2014;51(12):941-7.

[DOI:10.1080/10601325.2014.967078]

35. Nagaraju G, Prashanth S, Shastri M, Yathish K, Anupama C, Rangappa D. Electrochemical heavy metal detection, photocatalytic, photoluminescence, biodiesel production and antibacterial activities of Ag-ZnO nanomaterial. Materials Research Bulletin. 2017;94:54-63. [DOI:10.1016/i.materresbull.2017.05.043]
36. Badawy M, Riad OKM, Taher FA, Zaki SA. Chitosan and chitosan-zinc oxide nanocomposite inhibit expression of Lasl and Rhll genes and quorum sensing dependent virulence factors of Pseudomonas aeruginosa. International journal of biological macromolecules. 2020;149:1109-17.

[DOI:10.1016/j.ijbiomac.2020.02.019] [PMID]

37. Hosseininassab Nodoushan SA, Yadegari $S$, Moghim S, Isfahani BN, Fazeli $H$, Poursina F, et al. Distribution of the Strains of Multidrugresistant, Extensively Drug-resistant, and Pandrug-resistant Pseudomonas aeruginosa Isolates from Burn Patients. Adv Biomed Res. 2017;6:74. [DOI:10.4103/abr.abr_239_16] [PMID] [PMCID]

38. Nikbin VS, Aslani MM, Sharafi Z, Hashemipour $M$, Shahcheraghi $F$, Ebrahimipour GH. Molecular identification and detection of virulence genes among Pseudomonas aeruginosa isolated from different infectious origins. Iranian journal of microbiology. 2012;4(3):118-23.

39. Lee NY, Ko WC, Hsueh PR. Nanoparticles in the Treatment of Infections Caused by MultidrugResistant Organisms. Front Pharmacol. 2019;10:1153.

[DOI:10.3389/fphar.2019.01153] [PMID] [PMCID]

40. Sirelkhatim A, Mahmud S, Seeni A, Kaus NHM, Ann LC, Bakhori SKM, et al. Review on Zinc Oxide Nanoparticles: Antibacterial Activity and Toxicity Mechanism. Nano-micro letters. 2015;7(3):219-42. [DOI:10.1007/s40820-0150040-x] [PMID] [PMCID]

41. Qi L, Xu Z, Jiang X, Hu C, Zou X. Preparation and antibacterial activity of chitosan nanoparticles. Carbohydrate research. 2004;339(16):2693700.

[DOI:10.1016/i.carres.2004.09.007] [PMID]

42. Ali SG, Ansari MA, Alzohairy MA, Alomary MN, Jalal M, AlYahya S, et al. Effect of Biosynthesized ZnO Nanoparticles on Multi-Drug Resistant Pseudomonas Aeruginosa. Antibiotics (Basel, Switzerland). 2020;9(5).[PMID] [PMCID] [DOI:10.3390/antibiotics9050260]

43. Bayroodi E, Jalal R. Modulation of antibiotic resistance in Pseudomonas aeruginosa by $\mathrm{ZnO}$ nanoparticles. Iranian journal of microbiology. 2016;8(2):85-92.

44. Al-Shabib NA, Husain FM, Ahmed F, Khan RA, Ahmad I, Alsharaeh E, et al. Biogenic synthesis of Zinc oxide nanostructures from Nigella sativa 
seed: Prospective role as food packaging material inhibiting broad-spectrum quorum sensing and biofilm. Sci Rep. 2016;6:36761. [DOI:10.1038/srep36761] [PMID] [PMCID]

45. Cremonini $E$, Zonaro $E$, Donini $M$, Lampis $S$, Boaretti $M$, Dusi $S$, et al. Biogenic selenium nanoparticles: characterization, antimicrobial activity and effects on human dendritic cells and fibroblasts. Microbial biotechnology. 2016;9(6): 758-71. [DOI:10.1111/1751-7915.12374] [PMID] [PMCID]

46. Souza RCd, Haberbeck LU, Riella HG, Ribeiro DH, Carciofi BA. Antibacterial activity of zinc oxide nanoparticles synthesized by solochemical process. Brazilian Journal of Chemical Engineering. 2019;36:885-93.

[DOI:10.1590/0104-6632.20190362s20180027]
47. Saleh MM, Sadeq RA, Latif HKA, Abbas HA, Askoura M. Zinc oxide nanoparticles inhibits quorum sensing and virulence in Pseudomonas aeruginosa. Afr Health Sci. 2019;19(2):2043-55. [DOI:10.4314/ahs.v19i2.28] [PMID] [PMCID]

48. Prateeksha, Rao CV, Das AK, Barik SK, Singh BN. ZnO/Curcumin Nanocomposites for Enhanced Inhibition of Pseudomonas aeruginosa Virulence via LasR-RhIR Quorum Sensing Systems. Molecular pharmaceutics. 2019;16(8): 3399-413. [DOI:10.1021/acs.molpharmaceut.9b00179] [PMID]

49. Singh BR, Singh BN, Singh A, Khan W, Naqvi AH, Singh HB. Mycofabricated biosilver nanoparticles interrupt Pseudomonas aeruginosa quorum sensing systems. Sci Rep. 2015;5:13719. [DOI:10.1038/srep13719] [PMID] [PMCID] 